\title{
HIDDEN INFORMATION IN INFRARED SPECTRUM ON SAFETY CLOTHES
}

\author{
Jana Žiljak Gršić, Lidija Tepeš Golubić, Ula Leiner, Denis Jurečić
}
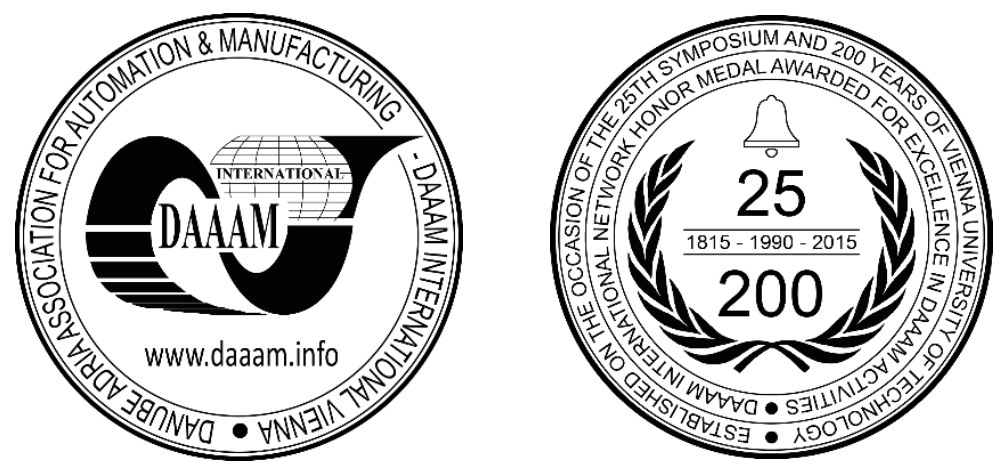

This Publication has to be referred as: Ziljak Grsic, J[ana]; Tepes Golubic, L[idija]; Ulla, L[einer] M[aksan] \& Jurecic, D[enis] (2017). Hidden Information in Infrared Spectrum on Safety Clothes, Proceedings of the 28th DAAAM International Symposium, pp.0237-0243, B. Katalinic (Ed.), Published by DAAAM International, ISBN 978-3-90273411-2, ISSN 1726-9679, Vienna, Austria

DOI: $10.2507 / 28$ th.daaam.proceedings.032

\begin{abstract}
We are observing duo images with double cameras that we have developed for the further development of infrared information VZ technology. The spectrum range goes from visual (V - RGB) to the near infrared spectrum (Z - NIR). We have developed procedures by reproducing a fine art work that contains a double image. The digital reproduction contains the same content from two images. The original fine work and the printing reproduction have been performed by different procedures, different dyes. Spectral analysis of painting and printing dyes has been performed. In this paper we are publishing a mathematical model of VZ separation of dyes in order to achieve reproduction of double images information on silk. The new model is based on twin dyes that have resulted from the experimental work with printing on silk and measuring their equality. We are using the spectral analysis of light absorption in the range from 400 to 1000 $\mathrm{nm}$. The goal is to find the shortest way to fix the content of process dyes in the ensuing printing experiments. The results of development of hidden image information are being demonstrated on safety clothes.
\end{abstract}

Keywords: infrared painting; near infrared spectroscopy; NIR reproduction; hidden image; camouflage uniform

\section{Introduction}

We have built the hidden information in documents [1], clothes [1], bank notes and packaging [1]. Double graphic solutions are on these products. The first one; for direct observation with naked eye. The second solution is being observed through a digital infrared camera. Art paintings have a double content considering the way of observation and the manner of painting. It has been established by spectrographic methods that painting dyes have different properties of sunlight absorption in the visual and near infrared spectrum [4].

Painters Nada Žiljak and Dijana Nazor create two pictures at the same place. 'Infrared painting' has been developed that is nowadays being successfully presented in galleries and museums. Figure 1 ( $a$ and $b$ ) is Nada's picture in double edition. The painter uses dozens of different dyes. Opposite to that, the reproduction of art paintings is being performed with process dyes C, M, Y, K. Only four dyes from the printing 'color practice'. Their absorption properties have been published in the article named: „Near infrared spektroskopy in print tehnology“ [5]. The richness of various dye tones for fine art is being simulated with just four dyes. 
We have developed the model of simulation of a big range of paints in the system of double images with cmyk printing dyes. We have asked the question: if the art painting has a duality, is it possible to simulate the painter's dyes with cmyk inks in digital print. The painter creates the Infrared painting in her own way. The innovation in this paper is based on the idea that there is that dual look into two light areas in the reproduction. The paintings have been taken from Sv. I. Zelina gallery where there is a large opus of modern infrared painting.

With this work we are expanding the topic of double information on textile, silk and artistic paintings. The first results of a forensic approach to art works has been demonstrated at the DAAAM symposium 2010 [9] with emphasis on "Hidden Information with Infraredesign". Products have been depicted as a pilot project during our second presentation 2014, (DAAAM Vienna 2014) [10]. The results of the INFRAREDESIGN procedure have been shown using the innovative design of topographic maps. An infrared method in the printing of special maps with integrated hidden information and recognition via IRD cameras has been introduced.

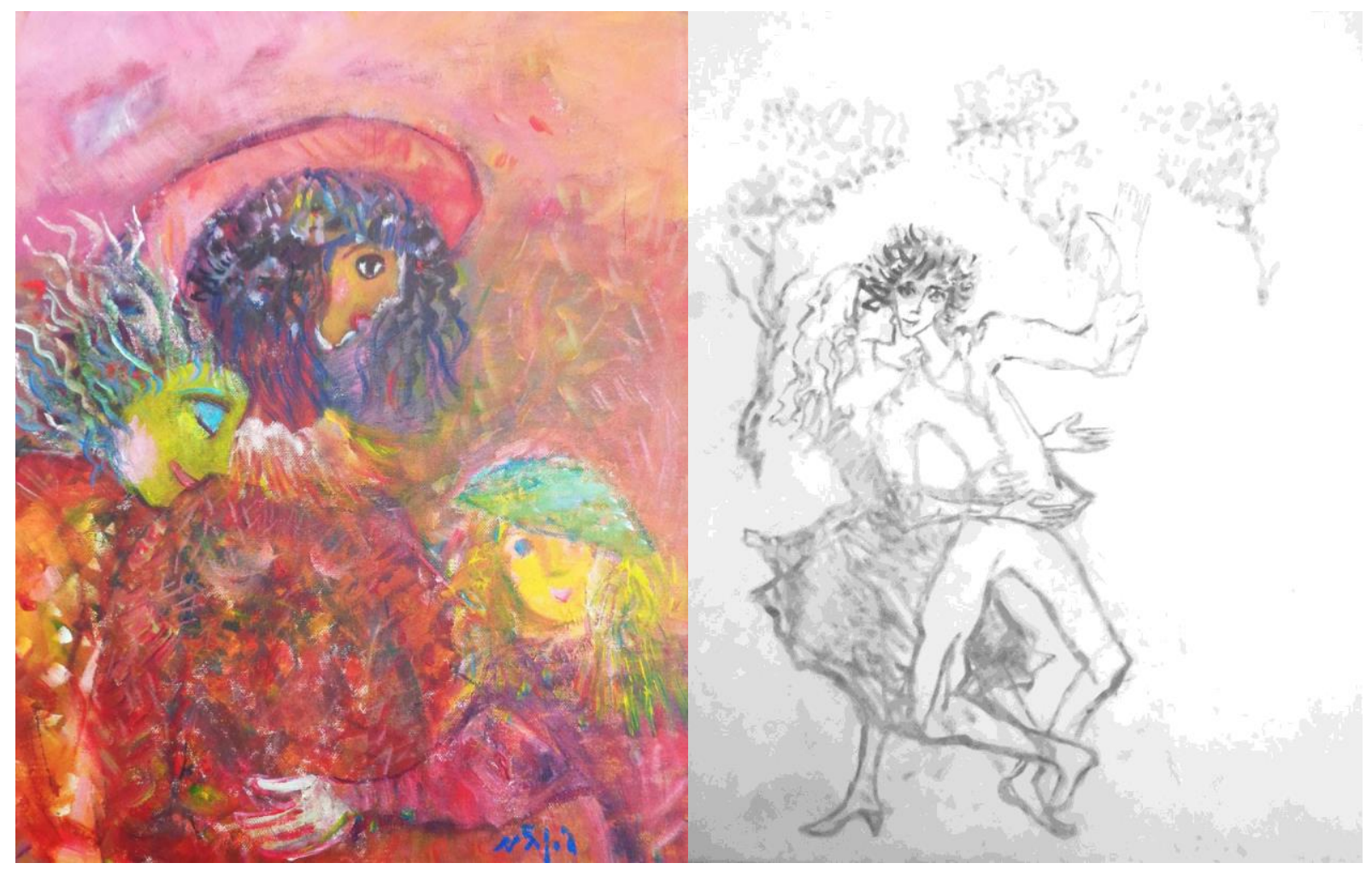

Fig. 1. Nada Žiljak. A double image, in a visible and near infrared Z-spectrum

\section{Spectrograms of painting dyes}

We have established spectrograms for painting dyes. Each dye has its own light absorption property in the visual (V) and near infrared spectrum (NIR-Z). Tube dyes (Burnt Umber, Cadmium Red Light, Ceruelan Blue, Phthalo Green) have been recorded with two cameras: $\mathrm{V}$ and $\mathrm{Z}$.
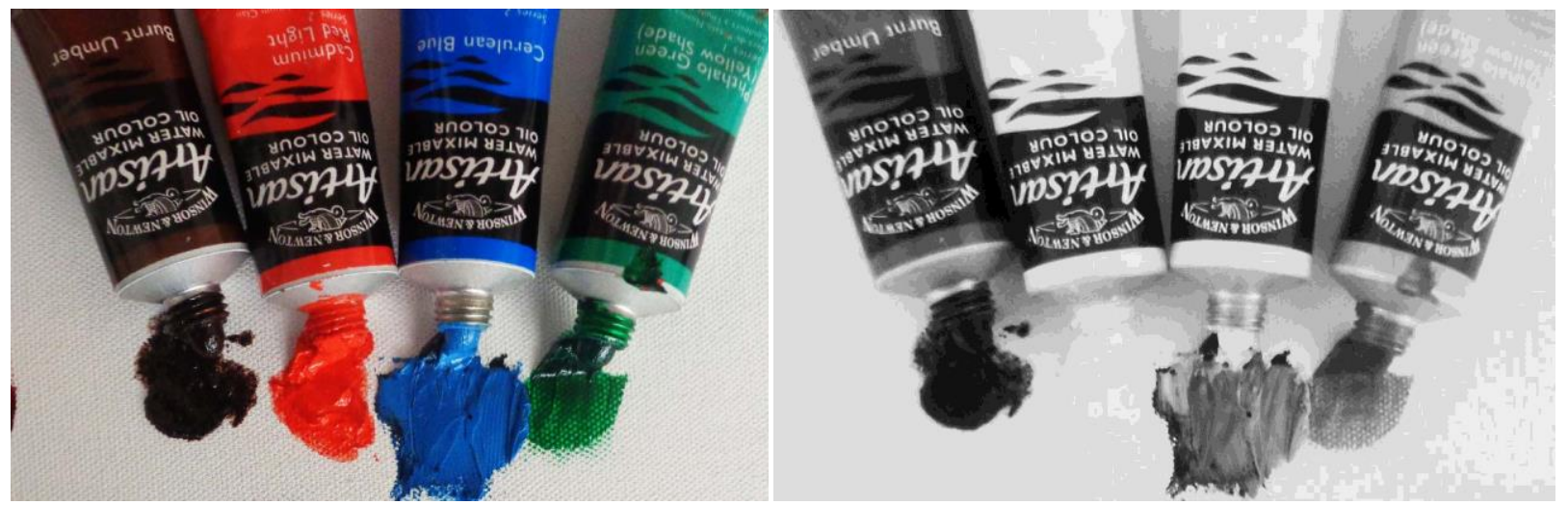

Fig. 2. ( $a$ and $b$ ) Tube dyes in $\mathrm{V}$ and $\mathrm{Z}$ spectrum 
Each dye splits into two areas for which the light absorption control in the visual and NIR spectrum is being performed. The goal is to achieve two desired pictures at the same place that are mutually hidden. The pictures are called ' $V$ ' and ' $\mathrm{Z}$ ' considering that they appear independently, reveal themselves in those light areas. Commercial dyes are being mixed according to the artists' plans and desires. New dyes with double VZ properties under the name of 'twin dyes' are being created.

On the graph, figure 3, we can see light absorption properties for a few commercial dyes in the field of fine art. Some dyes (brown and blue) have a significant response in the near infrared spectrum. Dyes: green and red, for example, do not have a response in the NIR spectrum.

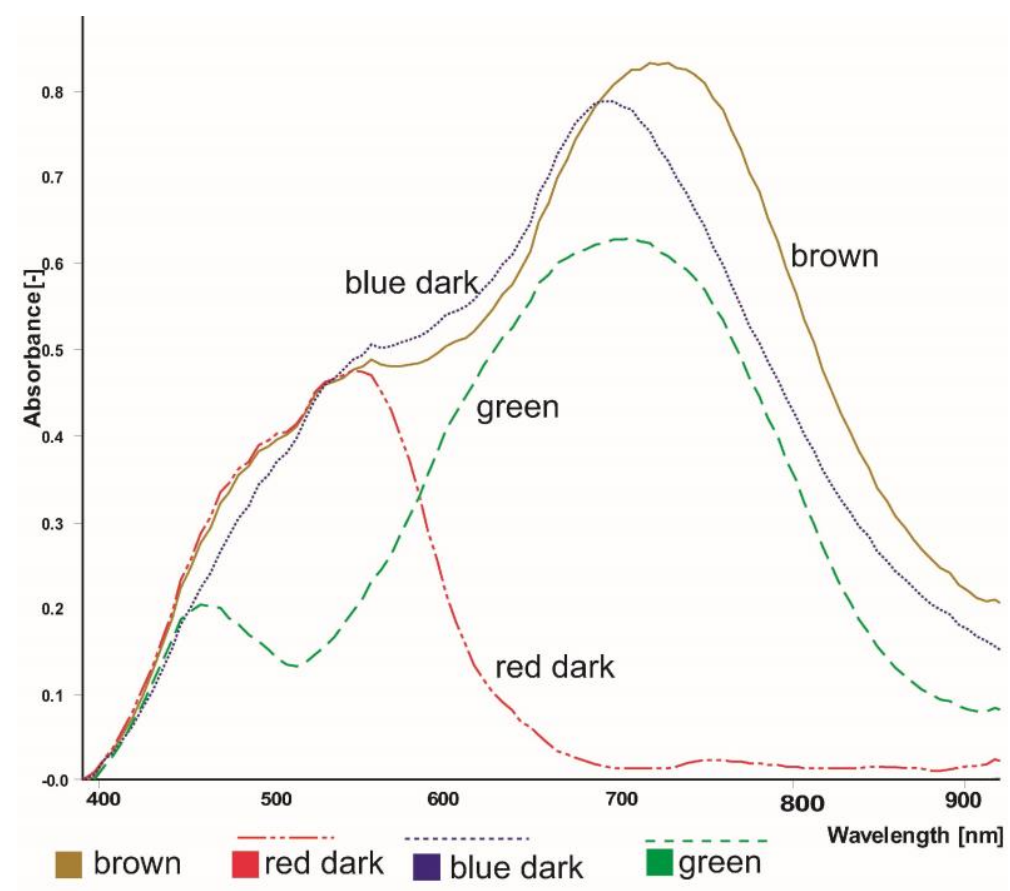

Fig. 3. Spectrograms of fine art dyes in the visual and near infrared spectrum

Dyes for color mixtures in the range from 400 to $900 \mathrm{~nm}$ have been studied through spectrograms. The analysis has introduced us to the field of 'twin dyes'. Those are pairs of dyes of identical colors in the visual spectrum but different in the near infrared $\mathrm{Z}$ spectrum. The painters have developed a new approach in art. The first step is development of 'twin dyes' by respecting the property of dye transparency in correlation with the thickness of in the layer 'color on color' coating. This innovation is the base for dual painting. Two dyes with an identical color tone in the visual spectrum and different near infrared spectrum absorption properties have enabled 'intimate painting' for a new way of observing a piece of art.

\section{Twin dyes for printing raster painting technology}

Table of twin dyes for printing: all the tones have an equal $\mathrm{K}$ value (carbon black) of $40 \%$. This will ensure the management of applying inks (dyes) and the plan of content in CMYKIR printing application with an intention to provoke a controlled appearance of the hidden image [6]. The new printing methods, expansion of the "twin dyes" idea, are being continued in the papers and patents in the field of safety print [7]. The base of the twin idea starts with grey dyes testing and accompanying rasterization with small line screens [8].

In table 1 you can find the results of the experimental search for twin dyes for printing on silk. After calculating regressive parameters for the entire color area using an INFRAREDESIGNR method, we are accessing the calculation of the following twin dye pairs. For some materials (military canvas (2)) the targeted color tones that exist in nature are being calculated: Forest areas, area of camouflage in the field, area of hiding in a sandy desert.

We are providing a mathematical model with which painting tones of artistic creations are being simulated. The goal is to achieve a reproduction of original art paintings and for them to have two independent images at the same place that are being separately observed with RGB (V) and NIR - (Z) cameras.

Two dyes of the dual system, their light absorption in the range from 400 to $900 \mathrm{~nm}$ have been shown in the graph, figure 4. Each dye has been performed in two ways of mixing, dye pairs of identical tone. 
Twins colours with: $\mathrm{C} 0=78, \mathrm{M} 0=63 ; \mathrm{Y} 0=54 \%$. Blue twins colour (print on silk) are composed of: $61 ; 25,15$ i $40 \%$ carbon black ink (HP 5000).

Red colour has values: $\mathrm{X} 0: \mathrm{C} 0=43, \mathrm{M} 0=95 ; \mathrm{Y} 0=95 \%$. Her twin colour Z (print on silk) is: 0; 76; $90 ;$ i $40 \% \mathrm{~K}$.

Red and blue colors have the same $\Delta \mathrm{Z}$ values at $900 \mathrm{~nm}$. The grey line at the bottom of the graph is the light absorption on pure silk on which the dress print has been performed.

\begin{tabular}{|c|c|c|c|c|c|c|c|c|}
\hline \multicolumn{3}{|c|}{$\begin{array}{c}\text { X0, \% } \\
\text { Co, M0, Y0 }\end{array}$} & \multicolumn{3}{|c|}{$\begin{array}{l}\text { X40, eksperimentalno } \\
\text { Blizanac za } K=\mathbf{4 0 \%}\end{array}$} & \multicolumn{3}{|c|}{$\begin{array}{c}\text { X40, C40, M40, Y40 } \\
\text { REGRESIJA za } \\
\text { K=40\% }\end{array}$} \\
\hline 73 & 91 & 94 & 45 & 65 & 84 & 41 & 62 & 74 \\
\hline 55 & 74 & 78 & 32 & 47 & 65 & 22 & 45 & 56 \\
\hline 89 & 96 & 50 & 67 & 64 & 11 & 76 & 67 & 23 \\
\hline 78 & 86 & 89 & 50 & 55 & 64 & 50 & 54 & 64 \\
\hline 42 & 55 & 56 & 10 & 25 & 26 & 11 & 24 & 28 \\
\hline 39 & 55 & 66 & 4 & 25 & 38 & 4 & 24 & 40 \\
\hline 40 & 44 & 43 & 11 & 11 & 9 & 13 & 29 & 6 \\
\hline 39 & 59 & 71 & 2 & 33 & 34 & 2 & 6 & 48 \\
\hline 35 & 40 & 40 & 1 & 6 & 10 & 7 & 31 & 6 \\
\hline 44 & 63 & 99 & 0 & 21 & 85 & 1 & 0 & 77 \\
\hline 95 & 50 & 95 & 60 & 0 & 40 & 72 & 5 & 44 \\
\hline 40 & 40 & 40 & 12 & 5 & 4 & 14 & 0 & 4 \\
\hline 87 & 48 & 81 & 67 & 1 & 33 & 66 & 0 & 32 \\
\hline 79 & 45 & 71 & 59 & 2 & 17 & 59 & 6 & 23 \\
\hline 67 & 47 & 47 & 52 & 2 & 2 & 49 & 6 & 3 \\
\hline 75 & 45 & 95 & 49 & 0 & 42 & 46 & 0 & 50 \\
\hline 85 & 48 & 48 & 77 & 0 & 0 & 73 & 3 & 0 \\
\hline 89 & 48 & 48 & 80 & 0 & 8 & 78 & 2 & 0 \\
\hline 75 & 48 & 48 & 68 & 9 & 8 & 59 & 6 & 2 \\
\hline 65 & 48 & 48 & 45 & 8 & 7 & 45 & 8 & 6 \\
\hline
\end{tabular}

Table 1. Twins dyes for silk

Twin dyes have an identical, similar light absorption in the visual area. Graphs of the same dye tone separate after 700 $\mathrm{nm}$. We call them $\mathrm{V}$ and $\mathrm{Z}$. Their difference is being manifested as a field in photographing with a NIR $-\mathrm{Z}$ camera. We added two sub-fields to INFRAREDESIGN® practice: $Z 1$ as the field of separation that needs to be skipped in these technologies (The naked eye sees something in that area).

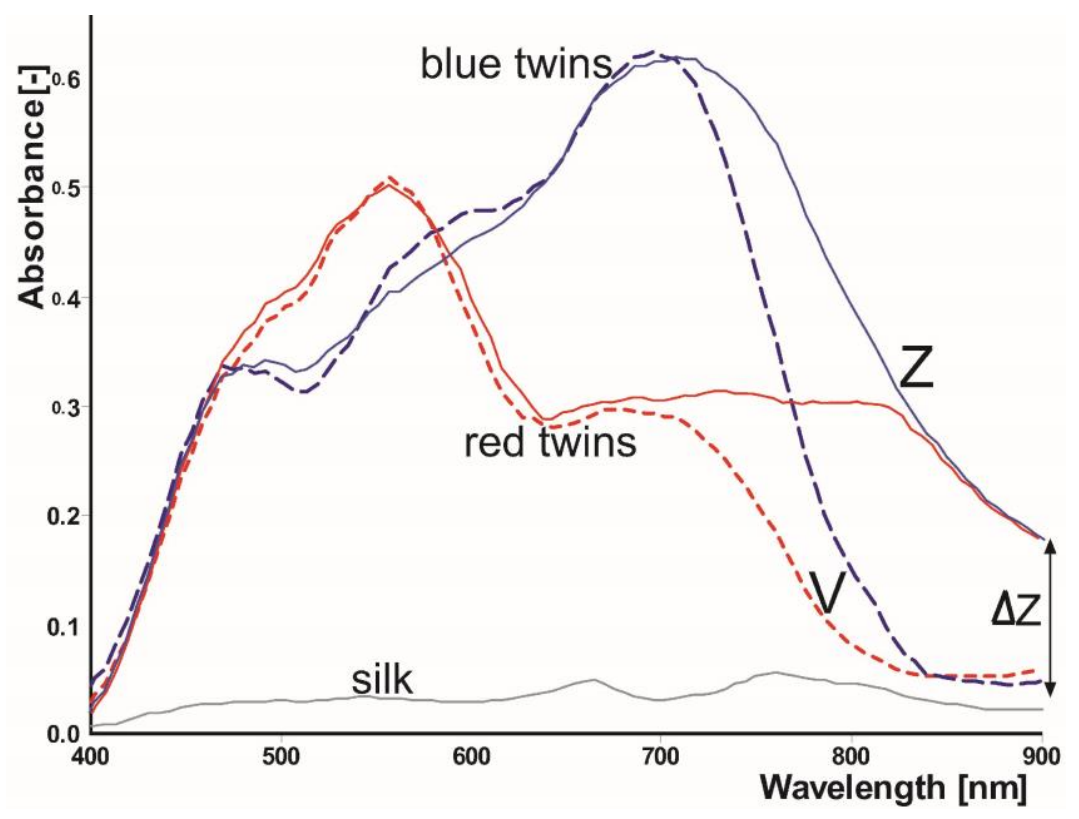

Fig. 4. Absorption of red and blue twins 
Light blocking for IRD technology starts at $850 \mathrm{~nm}$. We have set up a Z2 area that is blocked within 850 and $1000 \mathrm{~nm}$. We have modified the photo cameras for recording at $1000 \mathrm{~nm}$ for which we use the name Z-camera. All the recordings are being performed with two (RGB and Z) cameras simultaneously for the purpose of a subsequent joining of two photographs [6].

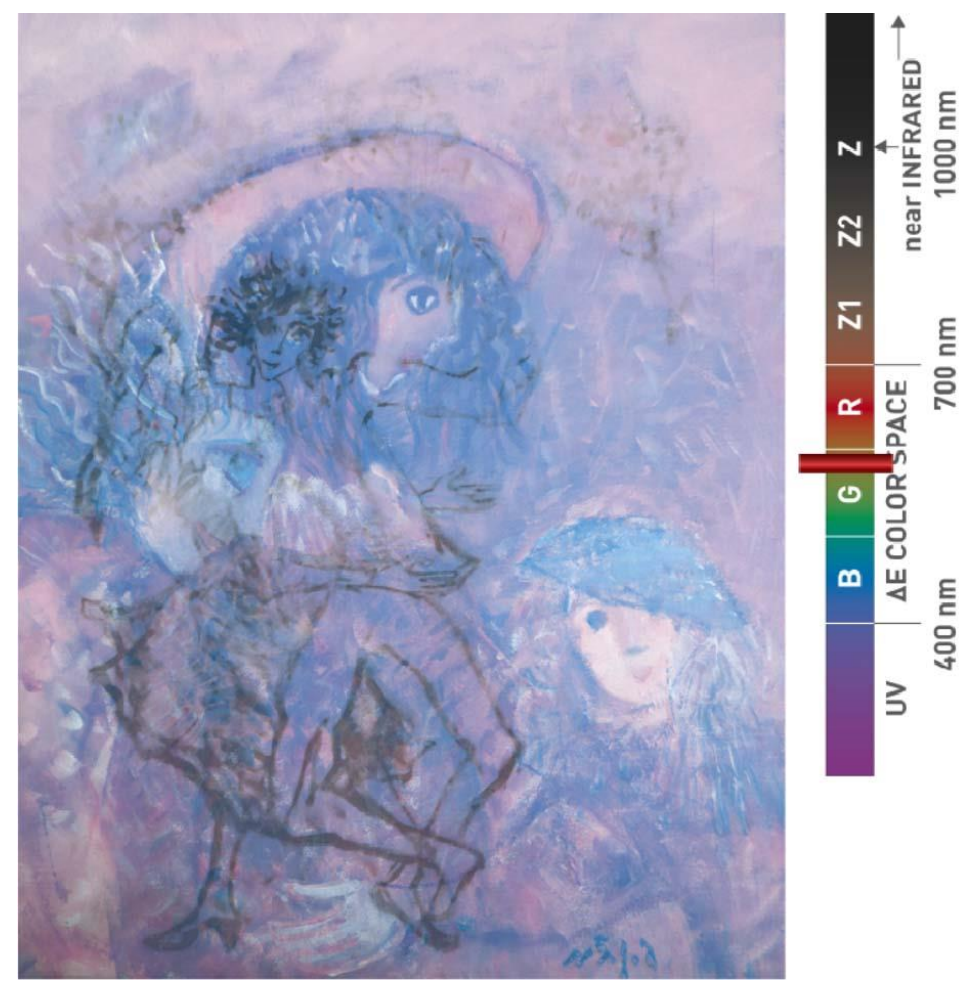

Fig. 5. InfraredArt; light with blocking from 400 to $1000 \mathrm{~nm}$ http://jana.ziljak.hr/NadaDam17.html or: http://jana.ziljak.hr/NadaDam17.swf

Figure 5 shows a simulation of continuous transition of light blockages from 400 to $1000 \mathrm{~nm}$. Animation of light blockage is being used for the control of vanishing and occurrence visible to the naked eye and invisible to the naked eye. The animation area includes V, Z1, Z2 areas. Digital control is being performed before printing with a model for printing on silk.

Model CMYKIR - v3, for silk that carries reproductions with process colors:

$$
\begin{aligned}
& \mathrm{C} 40=-0.287243907 * \mathrm{Y}-0.045801224 * \mathrm{M}+1.367575664 * \mathrm{C}-27.36785066 \\
& \mathrm{M} 40=-0.05868754 * \mathrm{Y}+1.358549444 * \mathrm{M}-0.277607606 * \mathrm{C}-36.05324188 \\
& \mathrm{Y} 40=1.058889627 * \mathrm{Y}+0.525560016 * \mathrm{M}-0.42510473 * \mathrm{C}-42.10206775
\end{aligned}
$$

The experimental process of calculating twin dyes is lasting. Print iterations and measurements of L*a*b values are being performed. Spectroscopy controls of twin dyes after print are being added for the final iterations. In table 2 you can find twin dyes that represent the expansion of the color field. The goal is to reduce the number of iterations of printing experiments. New twin dyes are the base for determining corrections of parameter coefficients in dependency equations X40 o X0. Eight New Calculated Critical Colors are in table 2.

\begin{tabular}{|ccc|ccc|}
\hline \multicolumn{3}{|c|}{ "X0, zadano } & \multicolumn{3}{c|}{ "Regresija } \\
C0, M0, Y0" & \multicolumn{2}{|c|}{ X40, M40, Y40" } \\
\hline 60 & 60 & 94 & 25 & 23 & 63 \\
42 & 95 & 45 & 13 & 79 & 18 \\
44 & 80 & 77 & 7 & 56 & 63 \\
44 & 50 & 50 & 16 & 17 & 18 \\
82 & 91 & 87 & 56 & 60 & 63 \\
36 & 36 & 36 & 10 & 1 & 0 \\
99 & 53 & 48 & 92 & 6 & 0 \\
\hline
\end{tabular}

Table 2. Examples of new "silk" twin colorants with $40 \% \mathrm{~K}$ 
The painting, acrylic on canvas by Nada Žiljak, has been recorded with two cameras. In equal resolutions and equal number of pixels. The first camera has recorded RGB $(3 \times 8$ bit $)$ in the visual $(V)$ spectrum, and the second camera is $\mathrm{Z}$ ( 8 bit) that records only one light absorption channel at $1000 \mathrm{~nm}$. Projectina cameras are being used that give information in 12 light blockages in $\mathrm{V}$ and $\mathrm{Z}$ area [4].

Twin dyes and new rules in printing: it is measured with the print on the same material (silk) and the dyes that are going to be used for printing. Change of order of dye application is later not allowed. Raster technique, covering of dyes, has been based on mutual transparency. We take this into calculation of the composition of raster elements for all combinations of printing technique and associated dyes. Measurements on digital print, for example, are valid only for the given combination of silk, ink and toner type. Change of material means: repeated measurements for creation of their twin sets.

\section{A dress with a reproduction of the art 'infrared painting'}

The new mathematical model for reproduction of the art painting on silk has been applied on HP5000 plotter with the associated UV inks. This is an expansion of the safety area for safety uniforms, unique clothes and preservation of the artwork's authenticity.

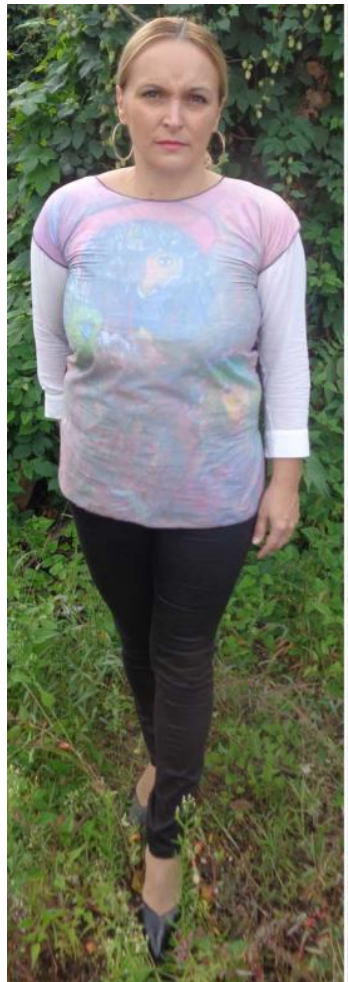

Fig. 6. (a and b). Infrared picture on a dress

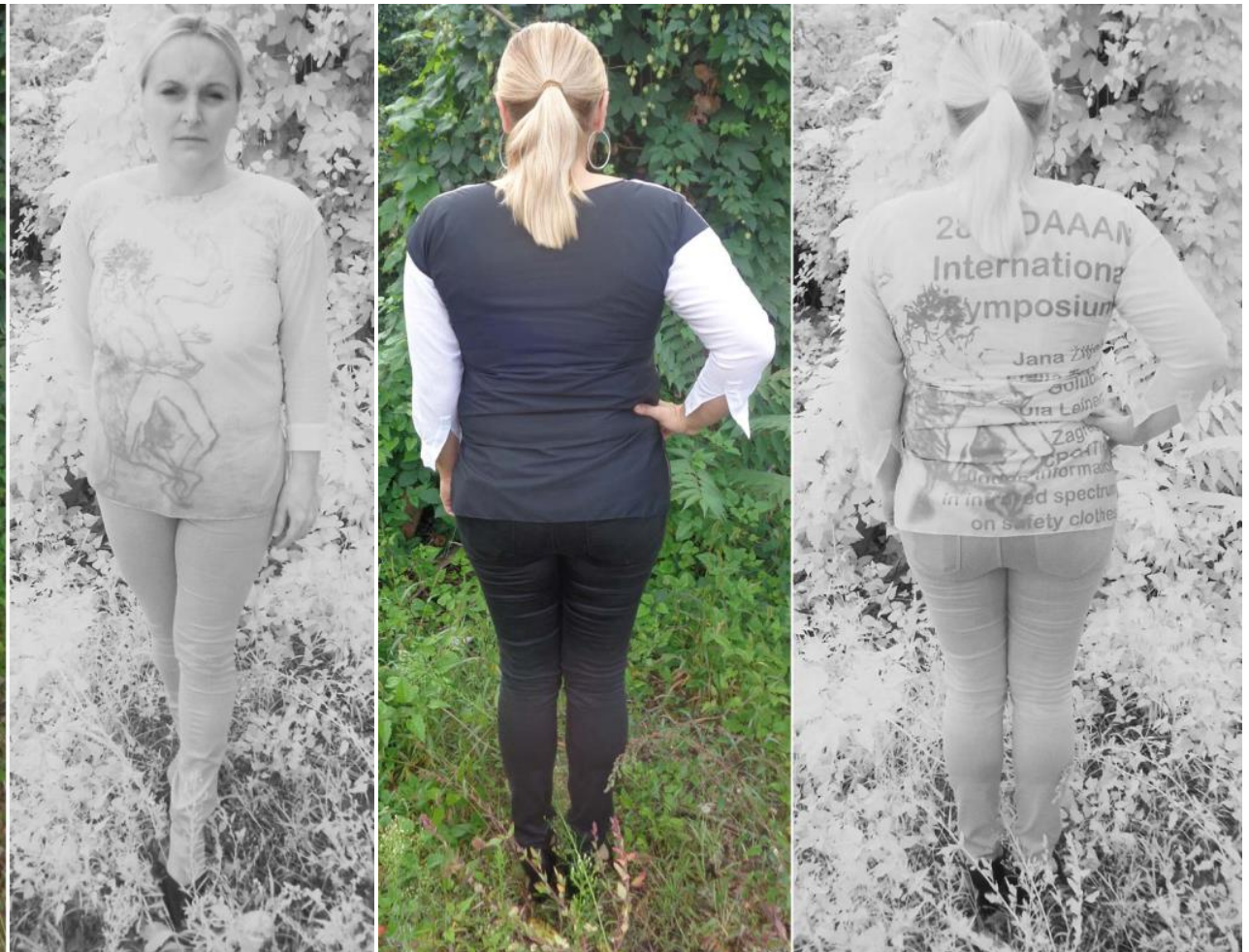

Fig. 7. (a and b). Infrared picture on black silk

The front part of the dress has been painted like the artist's painting. Visual and NIR pictures that are reproductions of the original are being observed with two cameras. Hidden data is the text about DAAAAM 2017 congress. On black canvas (back side of the dress) is a $\mathrm{Z}$ picture expanded with appropriate textual information: 28th DAAAM International Symposium Jana Žiljak, Lidija Tepeš Golubić, Ula Leiner, Denis Jurečić Zagreb, CROATIA Hidden information in infrared spectrum on safety clothes. The canvas itself reflects the near infrared light. For Z camera that canvas is 'white'.

\section{Conclusion}

The painters are given an innovative method of creating a double image. Such artwork represents an insurmountable problem in the restoration technology. This paper demonstrates the future reproductive practice of art paintings. Each technique of graphic reproduction that relies on dual art painting is a new challenge in understanding dye properties in two light areas. This idea of 'hidden reproduction' or the new term 'infrared painting' will spread to other printing technologies: offset, screen printing, high printing and different digital print technologies. For each change of materials and dyes it is necessary to establish new color settings, a new mathematical model of separation of printing dyes. We are facing a new challenge in development of safety print and VZ reproduction. This paper is an example of a union between art and science. 
These researches introduce new methods in the digital management of hidden information with printing processes. The use can be expanded to fine arts, a new form of painting that uses scientific methods of studying colour. The painters will start to use security principles to protect their works of art, as suggested in this article. Future research will be on the topic of colour spectroscopy for different applications. This will expand the procedures of understanding the properties of colour to an area beyond the reach of our eyes. New procedures will be opened in the forensic work of determining the origin of works of art.

\section{References}

[1] Aleksandra Bernašek, Ljilja Ivančević; Sigurnost u dizajnu dokumenata i vrijednosnicaSafety design of documents and securitie; Polytechnic \& Design (.tvz.hr); Zagreb University of applied sciences; Vol. 4, No. 1, 2016. pp: 60 67; ISSN 2459-6302; ISSN ;1849-1995; DOI: 10.19279/TVZ.PD.2016-4-1-08

[2] Ivana Ž. Stanimirović, Jana Ž. Vujić, Nikolina Stanić Loknar; Marking of the camouflage uniform for visual and near infrared spectrum, Technics Technologies Education Management, Vol 8. No3. 2013, p: 920 - 026, ISSN 18401503

[3] Martina Friščić, Olivera Međugorac, Lidija Tepeš, Denis Jurečić, Invisible information on the transparent polymer food packaging with Infra V/Z technology, TTEM Vol 8/4,/ 2013; P: 1512 -1519, ISSN:1840-1503, e-ISSN 1986$809 \mathrm{X}$

[4] Projectina AG Docucenter 4500, Switzerland, http://forensictechnology.com/projectina/

[5] Jana Žiljak; Near infrared spektroskopy in print tehnology; Polytechnic \& design Vol. 5, No. 1, 2017. pp:32-36; DOI: 10.19279/TVZ.PD.2017-5-1-05

[6] Pap, Klaudio; Žiljak, Ivana; Žiljak-Vujić, Jana; Image Reproduction for Near Infrared Spectrum and the Infraredesign Theory, Journal of Imaging Science and Technology, vol. 54, no. 1, pp. 10502-1-10502-9(9), 2010

[7] Li, C.; Wang, C.; Wang, S.J. A Black Generation Method for Black Ink Hiding Infrared Security Image. // Applied Mechanics and Materials, Trans Tech Publications, Switzerland, Vol. 262 (2013), pp. 9-12.

[8] Ivan Pogarčić, Ana Agić, Maja Matas; Evaluation of the colorant twins for the neutral grey spectra in infrared graphic procedure; Tehnički vjesnik 23, 6(2016), p:1659-1664; ISSN 1330-3651, ISSN 1848-6339; DOI: 10.17559/TV-20150303132036 ; Hrcak ID: 169526

[9] Jana Žiljak-Vujić; Ivana Žiljak Stanimirović; Ivan Pogarčić: "Hidden Information with Infraredesign", Annals of DAAAM for $2010 \&$ Proceedings of the 21st international DAAAM symposium intelligent manufacturing\&automation: focus on interdisciplinary solutions, Zadar, Croatia (ed. Branko Katalinic), (2010.), p. 249-250, ISSN: 1726-9679, ISBN: 978-3-901509-73-5

[10] Jana Žiljak Vujić, Maja Matas, Mateo Pogarčić, Ivana Žiljak Stanimirović: “ Topographic maps with infrared colors”, 25th DAAAM International Symposium on Intelligent Manufacturing and Automation, 2014, Vienna, 2014-10-27, p. 1-8, ISSN 1877-7058 (C) 2015 The Authors. Published by Elsevier Ltd.Peer-review under responsibility of DAAAM International Vienna. 